\title{
Surface PEGylation and Ligand Exchange Chemistry of FePt Nanoparticles for Biological Applications
}

Rui Hong ${ }^{\dagger}$, Nicholas O. Fischer ${ }^{\S}$, Todd Emrick ${ }^{\ddagger}$, Vincent M. Rotello ${ }^{\S t,}$

$\dagger$ Department of Chemistry, §Program in Molecular and Cellular Biology, $\ddagger$ Department of Polymer

Science and Engineering, University of Massachusetts, Amherst, MA 01003

\section{Supporting Information}

\section{Synthesis of Ligand 1, 2 and $\mathbf{3}$}

General: ${ }^{1} \mathrm{H}$ and ${ }^{13} \mathrm{C}$ NMR spectra were recorded on a Bruker $300 \mathrm{MHz}$ spectrometer. All the chemicals were purchased from Aldrich or Acros and were used without further purification. Solvents were purchased form Fisher Scientific or VWR and were used as received unless otherwise specified. Dichloromethane (DCM) was distilled over $\mathrm{CaH}_{2}$ and THF was distilled from sodium/benzyl ketyl.

\section{Synthesis of Dopamine-mPEG550 (Ligand 1)}
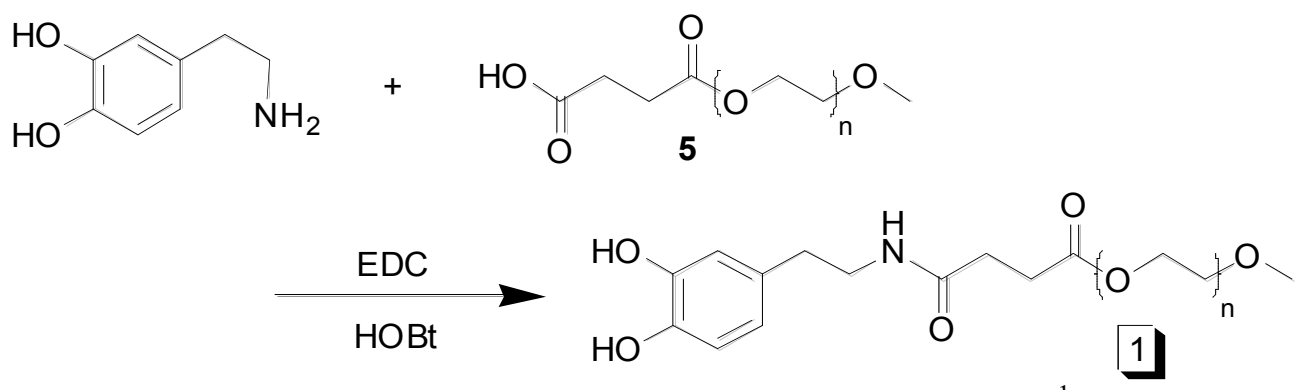

mPEG550 derivative 5 was synthesis by adopting a reported method. ${ }^{1}$

${ }^{1}$ H NMR $\left(300 \mathrm{MHz}, \mathrm{CDCl}_{3}\right)$ : $4.24(\mathrm{t}, 2 \mathrm{H}, \mathrm{J}=4.8 \mathrm{~Hz}), 3.52-3.68(\mathrm{~m}, \sim 44 \mathrm{H}), 3.36(\mathrm{~s}, 3 \mathrm{H})$, 2.63 (br-s, 4H).

${ }^{13}$ C NMR (75 MHz, $\left.\mathrm{CDCl}_{3}\right): 175.13,172.25,72.06,70.68-70.83,69.12,64.00,59.19$, $29.48,29.13$.

Dopamine-mPEG550 (ligand 1)

PEG-acid $(0.65 \mathrm{~g})$, HOBt $(0.135 \mathrm{~g})$ and DIPEA $(0.26 \mathrm{~g})$ were mixed in $5 \mathrm{ml}$ dry DMF and stirred at $0{ }^{\circ} \mathrm{C}$. EDC $(0.195 \mathrm{~g})$ was then added and the reaction solution was stirred for 5 minutes followed by the addition of dopamine hydrochloride $(0.2 \mathrm{~g})$. The mixture was purged with argon and stirred at $4{ }^{\circ} \mathrm{C}$ overnight. DMF was removed under vacuo and the residue was dissolved in $150 \mathrm{ml}$ chloroform. The organic was washed with cold $1 \mathrm{M}$ $\mathrm{HCl}$, st. $\mathrm{NaHCO}_{3}$, water and brine before dried over $\mathrm{MgSO}_{4}$. Solvent was removed and the residue was further dried under high vacuo to give a viscous oil $(0.45 \mathrm{~g})$.

${ }^{1}$ H NMR $\left(300 \mathrm{MHz}, \mathrm{CDCl}_{3}\right)$ : 6.78-6.80 (m, 1H), $6.70(\mathrm{~m}, 1 \mathrm{H}), 6.53-6.56(\mathrm{~m}, 1 \mathrm{H}), 6.10$ (s, br, 1H), 4.16-4.19 (m, 2H), 3.52-3.62 (m, 44H), 3.40-3.47 (m, 2H), $3.36(\mathrm{~s}, 3 \mathrm{H})$, 2.63-2.70 (m, 4H), $2.42(\mathrm{t}, 2 \mathrm{H}, \mathrm{J}=6.6 \mathrm{~Hz})$.

${ }^{13}$ C NMR (75 MHz, $\mathrm{CDCl}_{3} / \mathrm{d}_{6}$-DMSO): 172.52, 171.36, 144.36, 142.87, 130.53, 119.87, $115.60,115.20,71.53,70.09-70.15,68.61,63.35,58.63,40.72,34.53,30.44,29.26$. 


\section{Synthesis of Thiol-mPEG550 (Ligand 2):}

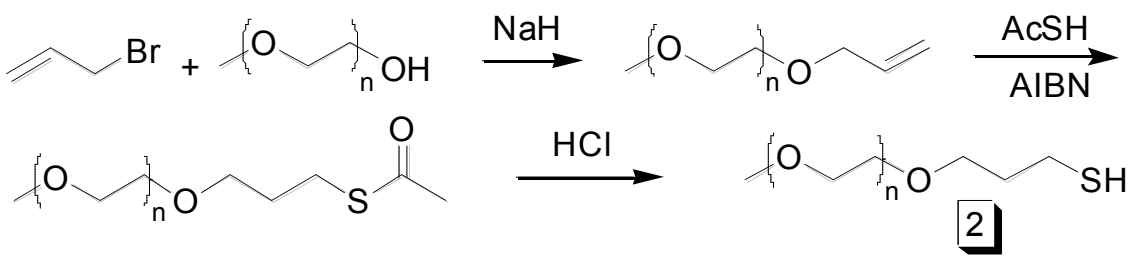

Allyl-mPEG550:

Polyethylene glycol monomethyl ether 550 (mPEG550) (11 g) in THF was added sodium hydride $(0.6 \mathrm{~g})$ at $0{ }^{\circ} \mathrm{C}$. The mixture was stirred for 5 minutes before allyl bromide $(3.02$ g) was added dropwisely. The reaction solution was allowed to warm up to room temperature. The reaction was then slowly heated to $40{ }^{\circ} \mathrm{C}$ and kept overnight. The reaction was cooled and quenched by adding ice slowly. THF was removed and the residue was added water and washed with hexane before extracted with methylene chloride (150 $\mathrm{ml} \mathrm{X} \mathrm{3).} \mathrm{Combined} \mathrm{organic} \mathrm{solution} \mathrm{was} \mathrm{washed} \mathrm{with} \mathrm{water} \mathrm{and} \mathrm{brine}$ before dried over $\mathrm{MgSO}_{4}$. Evaporation of the solvent afforded a viscous liquid in $84 \%$ yield.

${ }^{1} \mathbf{H}$ NMR (300 MHz, $\left.\mathrm{CDCl}_{3}\right): 5.88$ (m, 1H), 5.13-5.28 (m, 2H), 3.99 (m, 2H), 3.51-3.62 $(\mathrm{m}, \sim 44 \mathrm{H}), 3.35(\mathrm{~s}, 3 \mathrm{H})$.

${ }^{13}$ C NMR (75 MHz, $\left.\mathrm{CDCl}_{3}\right): 134.91,117.25,72.38,72.07,70.77,70.72,70.67,69.56$, 59.19.

Thioester:

Allyl-mPEG550 from above reaction (3.5 g) in THF was added thioacetic acid (2.28 g) and AIBN $(0.3 \mathrm{~g})$. The solution was purged with Ar for 5 minutes before refluxed for 10 hours under nitrogen. THF was removed and the residue was dissolved in DCM. The mixture was washed with saturated $\mathrm{NaHCO}_{3}$, water and brine and dried over $\mathrm{MgSO}_{4}$. After removal of the solvent, the product was purified by column chromatography (silica gel, EtOAc to EtOAc/MeOH). The thioester was obtained as a pale yellow oil in $65 \%$ yield.

${ }^{1}$ H NMR (300 MHz, $\left.\mathrm{CDCl}_{3}\right): 3.52-3.64(\mathrm{~m}, \sim 44 \mathrm{H}), 3.49(\mathrm{t}, 2 \mathrm{H}, \mathrm{J}=6.3 \mathrm{~Hz}), 3.36(\mathrm{~s}, 3 \mathrm{H})$, $2.92(\mathrm{t}, 2 \mathrm{H}, \mathrm{J}=7.2 \mathrm{~Hz}), 2.30(\mathrm{~s}, 3 \mathrm{H}), 1.83(\mathrm{~m}, 2 \mathrm{H})$.

${ }^{13}$ C NMR (75 MHz, $\left.\mathrm{CDCl}_{3}\right):$ 196.04, 72.09, 70.73, 70.68, 70.36, 69.72, 59.21, 30.80, $29.72,26.14$.

\section{Thiol-mPEG550}

Thioester $(0.66 \mathrm{~g})$ was dissolved in $25 \mathrm{ml} \mathrm{MeOH}$ and the solution was purged with agron for 10 minutes. Acetyl chloride $(0.18 \mathrm{ml})$ was added slowly to the solution. The reaction was refluxed under nitrogen overnight. After removal of the solvent, the residue was further dried under high vacuo to afford the thiol in $95 \%$ yield.

${ }^{1}$ H NMR (300 MHz, $\left.\mathrm{CDCl}_{3}\right): 3.53-3.70$ (m, 46 H), 3.37 (s, 3H), 2.60 (dd, 2H), 1.87 (m, 2H), 1.37 (t, 1H, J=8.1 Hz).

${ }^{13}$ C NMR (75 MHz, $\left.\mathrm{CDCl}_{3}\right):$ 72.14, 70.43-70.78, 69.30, 59.26, 33.93, 21.65.

MS (ESI): calcd. $546.3(\mathrm{n}=10), 590.3(\mathrm{n}=11), 634.3(\mathrm{n}=12)$; found $525.3\left(\mathrm{n}=9, \mathrm{M}+\mathrm{Na}^{+}\right)$, $569.3\left(\mathrm{n}=10, \mathrm{M}+\mathrm{Na}^{+}\right), 613.4\left(\mathrm{n}=11, \mathrm{M}+\mathrm{Na}^{+}\right), 657.4\left(\mathrm{n}=12, \mathrm{M}+\mathrm{Na}^{+}\right), 701.4(\mathrm{n}=13$, $\left.\mathrm{M}+\mathrm{Na}^{+}\right)$. 


\section{Synthesis of Thiol-TEG-ammonium Ligand 3:}

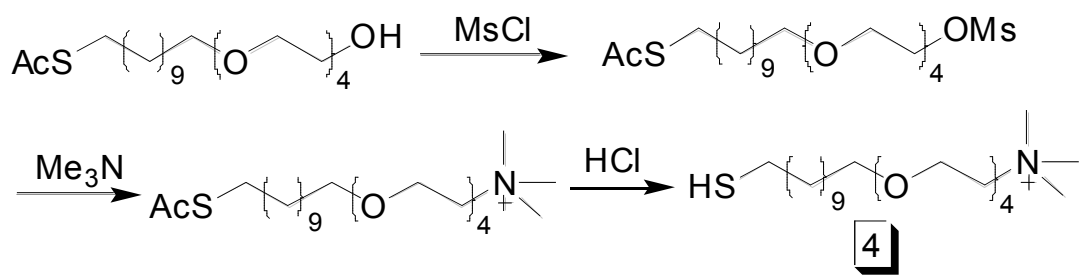

Methanesulfonic acid ester:

To a solution of [1-[(Methylcarbonyl)thio]undec-11-yl]tetra(ethylene glycol) (5 mmol) in $50 \mathrm{ml}$ dry DCM was added $\mathrm{Et}_{3} \mathrm{~N}(7.5 \mathrm{mmol})$ and the mixture was cooled to $0{ }^{\circ} \mathrm{C}$. Methanesulfonyl chloride $(5.5 \mathrm{mmol})$ was added over a period of several minutes into the solution. The reaction was allowed to worm up to room temperature and stirred under $\mathrm{N}_{2}$ for one more hour. After the completion of the reaction (monitored by TLC), the mixture was washed with ice water, $1 \mathrm{M} \mathrm{HCl}$, water, $\mathrm{NaHCO}_{3}$ and brine before it was dried over $\mathrm{MgSO}_{4}$. Evaporation of the solvent afforded a pale yellow oil in quantitative yield. The product was found to be clean by TLC and NMR.

${ }^{1}$ H NMR (300 MHz, CDCl $)$ ) $4.38(\mathrm{~m}, 2 \mathrm{H}), 3.56-3.78(\mathrm{~m}, 14 \mathrm{H}), 3.39$ (t, 2H, J=6.9 Hz), $3.08(\mathrm{~s}, 3 \mathrm{H}), 2.30(\mathrm{~s}, 3 \mathrm{H}), 1.26-1.57(\mathrm{~m}, 18 \mathrm{H})$.

${ }^{13}$ C NMR (75 MHz, $\left.\mathrm{CDCl}_{3}\right): 26.19,28.92,29.21,29.25,29.56,29.57,29.61,29.66$, $29.73,30.77,37.84,69.13,69.26,70.15,70.63,70.70,70.74,71.65,196.18$.

[2-(2-\{2-[2-(11-Mercapto-undecyloxy)-ethoxy]-ethoxy $\}$-ethoxy)-ethyl]-trimethyl ammonium methanesulfonate:

Methenasulfonic acid ester $5(5 \mathrm{mmol})$ in $10 \mathrm{ml} \mathrm{EtOH}$ was added $6 \mathrm{ml} \mathrm{Me}_{3} \mathrm{~N}(33 \%$ in $\mathrm{EtOH}, 25 \mathrm{mmol})$. The mixture was stirred under $\mathrm{N}_{2}$ at room temperature until the disappearance of the starting material by TLC. The mixture was concentrated in vacuo and was triturated with hexane/ether $(1: 1)$ for at least 3 times. The insoluble oil was further dried under vacuum. The thiol deprotection reaction was conducted in acidic conditions by refluxing the thiolester in $0.1 \mathrm{M}$ methanolic $\mathrm{HCl}$ overnight under argon. The mixture was concentrated and was triturated with ether. The insoluble material was collected and dried under vacuo to give compound 5 in $90 \%$ yield.

${ }^{1}$ H NMR: $3.95(\mathrm{~m}, 2 \mathrm{H}), 3.83(\mathrm{~m}, 2 \mathrm{H}), 3.37(\mathrm{~s}, 9 \mathrm{H}), 3.39-3.66(\mathrm{~m}, 14 \mathrm{H}), 2.81(\mathrm{~s}, 3 \mathrm{H})$, $2.50(\mathrm{~m}, 2 \mathrm{H}), 1.52-1.63(\mathrm{~m}, 4 \mathrm{H}), 1.25-1.34(\mathrm{~m}, 15 \mathrm{H})$.

${ }^{13}$ C NMR: $24.83,26.24,28.53,29.23,29.66,29.74,29.79,34.21,39.70,54.80,65.36$, 65.77, 70.19-70.71, 71.69.

MS (ESI): calcd. for $\mathrm{C}_{22} \mathrm{H}_{48} \mathrm{NO}_{4} \mathrm{~S}^{+} 422.3$, found 422.4 . 
Figure S1. Histograms of MNPs as shown in TEM of Figure 2.
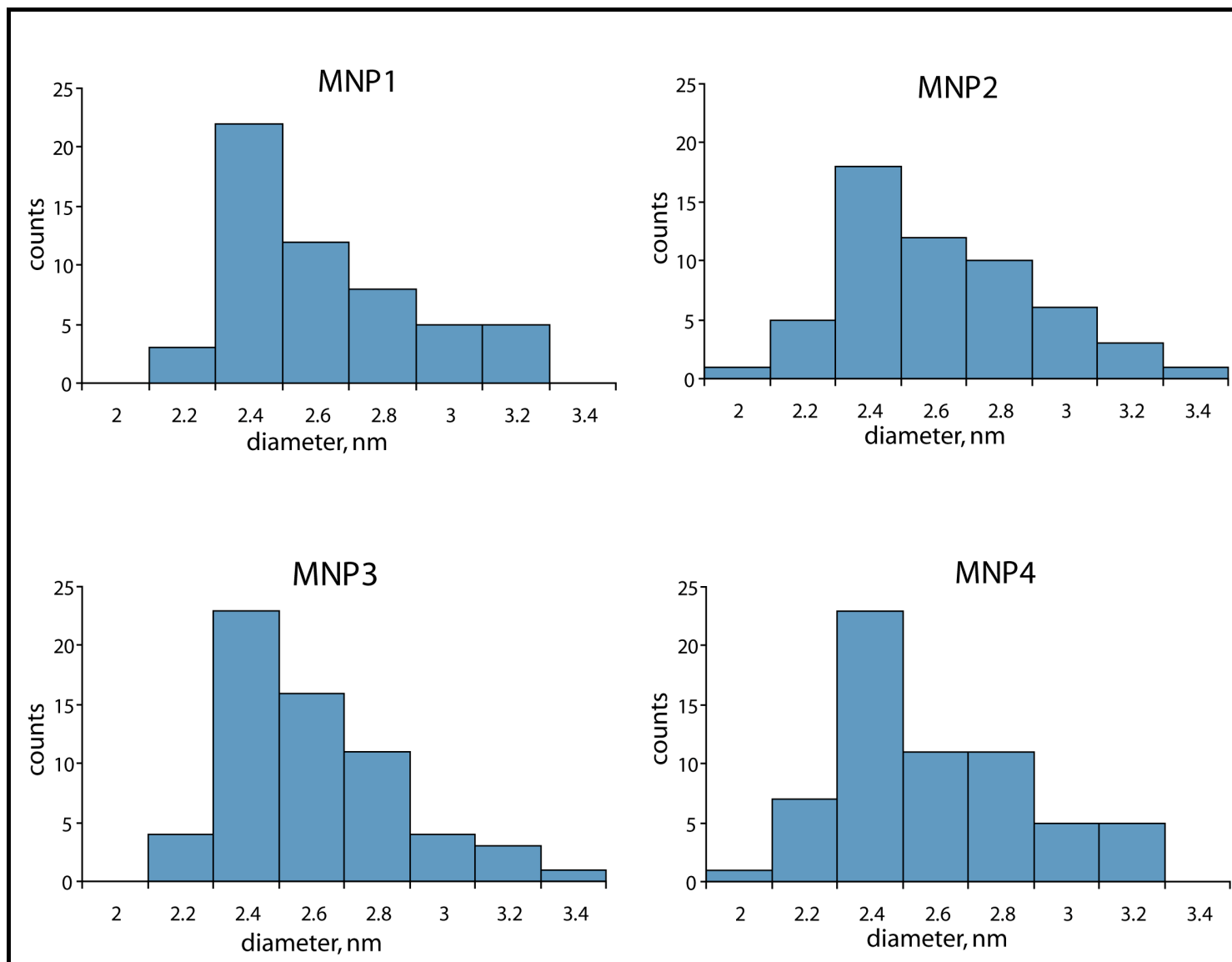

1. Parrish, B.; Emrick, T. Macromolecules 2004, 37, 5863-5865. 